\title{
Interferências e Contaminações na Análise de Resíduos de Pesticidas
}

\author{
CELESTE DE MATOS LINO e MARIA IRENE O.C.B.NORONHA DA SILVEIRA*
}

Neste trabalho os autores referem uma série de interferências

e contaminações com as quais os analistas se podem confrontar no decurso da análise de resíduos de pesticidas.

\section{INTRODUÇÃO}

Constituem objectivo deste trabalho algumas considerações julgadas oportunas no sentido de proporcionar uma melhor prática analítica quando da determinação de resíduos de pesticidas por cromatografia gáslíquido. Na realidade, dado tratar-se de quantidades muito baixas, um cromatograma pode reflectir não somente os resíduos de pesticidas mas também os contaminantes resultantes de todo o manuseamento anterior ao processo analítico, os contaminantes introduzidos pelo ambiente laboratorial, os co-extractivos presentes nas soluções das amostras. bem como as interferências ligados ao próprio sistema analítico.

\section{A. Interferências e}

\section{contaminações anteriores} ao processo analítico

Antes da determinação analítica deve atender-se a que os recipientes a utilizar no envio das amostras ao laboratório e na sua posterior conservação não devem, em nenhuma circunstância, ser constituídos por plástico dada a sua composição em ftalatos [1;2] e / ou bifenilos policlorados [3; 4]. São igualmente de excluir materiais constituídos por cloreto de polivinilo [5; 6], em virtude da presença de átomos de cloro na sua molécula e um conteúdo em plastificantes num teor que excede os $20 \%$. O mesmo requisito é mantido para as tampas dos respectivos recipientes. A borracha deve ser igualmente evitada. Os compostos designados originam interferências na detecção analítica quando se analisam hidrocarbonetos clorados devido à sua afinidade para captar electrões [7-10]. O contacto com o papel deve também ser evitado, pois a presença de ftalatos e outros compos- tos interferem nas determinações do $\beta$-HCH e do p,p'DDT [11].

Por vezes, o revestimento interior das tampas dos recipientes de vidro contém ésteres de ácido fosfórico, voláteis, originando o aparecimento de picos interferentes quando se opera com o detector de ionização de chama alcalina, usado na detecção e quantificação de resíduos de organofosforados [10].

Preferencialmente, deve ser usado vidro de boa qualidade na conservação e manipulação das amostras. No caso dos resíduos de organoclorados, pode-se recorrer ao aço inoxidável; os recipientes para amostras sólidas devem ser revestidos com folha de alumínio e os destinados a amostras líquidas, solventes ou soluções orgânicas devem ser revestidos com politetrafluoroetileno (PTFE) [6].

Durante o envio das amostras ao laboratório podem surgir problemas de contaminação resultantes de um acondicionamento precário das mesmas, podendo este ser causa do rebentamento e contacto das amos-<smiles>Cc1c([N+](=O)[O-])c(C)c([N+](=O)[O-])c(C(C)(C)C)c1[N+](=O)[O-]</smiles>

ALMISCAR-XILOL<smiles>Cc1c(C)c([N+](=O)[O-])c(C(C)(C)C)c([N+](=O)[O-])c1C</smiles><smiles>COc1c(C(C)(C)C)cc([N+](=O)[O-])c(C)c1[N+](=O)[O-]</smiles>
ALMÍSCAR-AMBRETA<smiles>CC(=O)c1c(C)c([N+](=O)[O-])c(C(C)(C)C)c([N+](=O)[O-])c1C</smiles>

tras com o gelo usado na sua refrigeração.

\section{B. Interferências e contaminações relacionadas com o ambiente laboratorial}

O polimento dos soalhos no laboratório deve ser mantido num mínimo. Produtos de limpeza como sabões, detergentes, loções e outros produtos como perfumes e cremes das mãos, contêm na sua composição almíscares sintéticos possuidores de grupos nitro como, por exemplo, o almíscar-xilol, almíscar- ambreta, almíscar-tibeteno e almíscar-cetona (Figura 1).

Estes compostos podem provocar contaminações na preparação da amostra mais do que através da contaminação ambiental. Yurawecz e Puma [12] referem a contaminação de amostras de peixe da família dos silúridas por estes aromas, manifestada através da ocorrência de picos situados na zona dos organoclorados $\mathrm{e}$ bifenilos policlorados, quando se usa o detector de captura de electrões.

$\mathrm{C}\left(\mathrm{CH}_{3}\right)_{3}$ 
Aqueles compostos também dão resposta no detector azoto-fósforo.

A contaminação pode também surgir de cosméticos, medicamentos e formulações hortícolas domésticas introduzidas no laboratório pelos funcionários ou visitantes [6].

Os filtros de lã de vidro dos sistemas de ar condicionado dos laboratórios são revestidos com tris (2-cloroetil)fosfato (TCEP), composto que origina o aparecimento de um pico interferente, próximo do ometoato, provocando um aumento da linha de base [13]. Aquele composto juntamente com outros ésteres do ácido fosfórico, como o tri-n-butilfosfato (TBP) e o tri-iso-butilfosfato (TIBP), usados não só como retardadores de fogo, mas também como plastificantes, foram encontrados como interferentes por Galassi e Guzzella [14] ao procederem à análise da triazina em amostras de águas potáveis e superficiais. Estes compostos foram detectados e quantificados por cromatografia gás-líquido com detector azotofósforo.

\section{Interferências e contaminações relativas ao processo analítico}

\section{C.1. Material de vidro}

O recurso aos solventes orgânicos para lavagem ou enxaguamento de material de laboratório deve, segundo alguns autores, ser evitado por três razões fundamentais: o seu alto custo (pureza elevada e grandes volumes), problemas de contaminação por adsorção e aumento de riscos para a saúde dos manipuladores [5; 6].

Alguns detergentes usados na lavagem do material de vidro introduzem impurezas nos solventes que interferem na detecção [15], pelo que é preferível utilizar um líquido biologicamente activo na sua lavagem, seguido de passagem por água destilada e secagem em estufa a $200^{\circ}-300^{\circ} \mathrm{C}$ [6]. Lamberton e Claeys [16] referem a descontaminação do material de vidro, destinado à análise de resíduos de organoclorados, em estufa a $230^{\circ} \mathrm{C}$, pois os oxidantes fortes e o metanol são ineficazes na remoção dos contaminantes. Ballschmiter [5] refere o seu aquecimento a $400^{\circ} \mathrm{C}$ numa corrente de azoto purificado pelo carvão.

O material de vidro usado na preparação das soluções padrão deve ser manuseado de forma adequada [5].

\section{C.2. Solventes: grau de pureza}

No decurso da análise de resíduos de pesticidas, os solventes são concentrados, o que proporciona um aumento da quantidade de impurezas a níveis que podem interferir com a detecção dos resíduos, por aumento do sinal da linha de base e redução da sensibilidade [6; 17].

Daqui se infere que os solventes orgânicos a utilizar na análise de resíduos de pesticidas devam possuir a máxima pureza sendo mesmo os de grau pró-análise submetidos a purificação adequada. O processo mais vulgarmente empregue na sua purificação é a destilação fraccionada. conduzida em sistema de vidro, normalmente sobre sódio metálico, quando apresentam pontos de ebulição acima do ponto de fusão do sódio.

Os solventes próprios para a análise de resíduos de pesticidas, apesar do preço mais elevado, são preferenciais para laboratórios com pequeno volume de amostras, para analistas que não disponham de tempo e espaço para purificar os solventes e para os iniciados em análise de resíduos, eliminando desta forma os problemas potenciais levantados pelas impurezas dos solventes e os perigos encontrados na purificação dos mesmos [15; 18].

Quando um novo lote de solvente entra na linha de análise deve ser testado no que respeita à pureza, tomando o mesmo volume, submetendo-o aos mesmos processos utilizados no método e examinando o concentrado por cromatografia gasosa. O concentrado não deve provocar uma deflexão da linha de base superior a $1 \mathrm{~mm}$, durante 2 a $60 \mathrm{minu}$ tos, após a injecção $[19 ; 20]$. Para além da execução do teste de pureza, em cada série de análises é necessário proceder à introdução de um branco que corra todo o processo, de forma similar à amostra, para garante da ausência de picos estranhos oriundos dos solventes [18].

Sempre que for possivel efectuar uma escolha, os solventes a utilizar devem possuir a menor toxicidade e o menor poder inflamável, uma vez que mesmo uma boa ventilação e técnica não impedem o escape de alguns vapores para o ambiente.

A exposição dos reagentes à atmosfera é de evitar, pois, mesmo quando por curtos períodos de tempo, pode provocar uma contaminação significativa [6]. A introdução de pipetas no frasco de solventes constitui igualmente uma prática impeditiva da manutenção de uma boa qualidade dos mesmos, bem como o seu contacto com material plástico, polietileno e borracha $[18 ; 21]$.

\section{C.3. Água}

A água usada na análise de resíduos de pesticidas destina-se à preparação de soluções aquosas de sais, como a de sulfato de sódio e/ou a de cloreto de sódio para obstar aos problemas de emulsão na partição líquido-líquido, à desactivação de adsorventes, à separação de um dos solventes usado na partição líquido-líquido (rejeitando-a ou não consoante a afinidade química dos pesticidas a determinar), ao ajuste do $\mathrm{pH}$ de misturas com soluções aquosas acídicas ou básicas [22], à eliminação (em certos substratos) dos açúcares responsáveis pela deterioração das seringas aquando da injecção dos extractos não purificados [23], e à extracção de resíduos de pesticidas em alimentos com baixo teor em humidade $(<10 \%)$, em mistura com outro solvente [24, p.18-19].

Sendo proveniente de um qualquer sistema de destilação ou desionização, a água pode conter contaminantes provenientes quer das resinas trocadoras de iões revestidos com cloreto de polivinilo, quer das ligações de plástico ou de materiais 


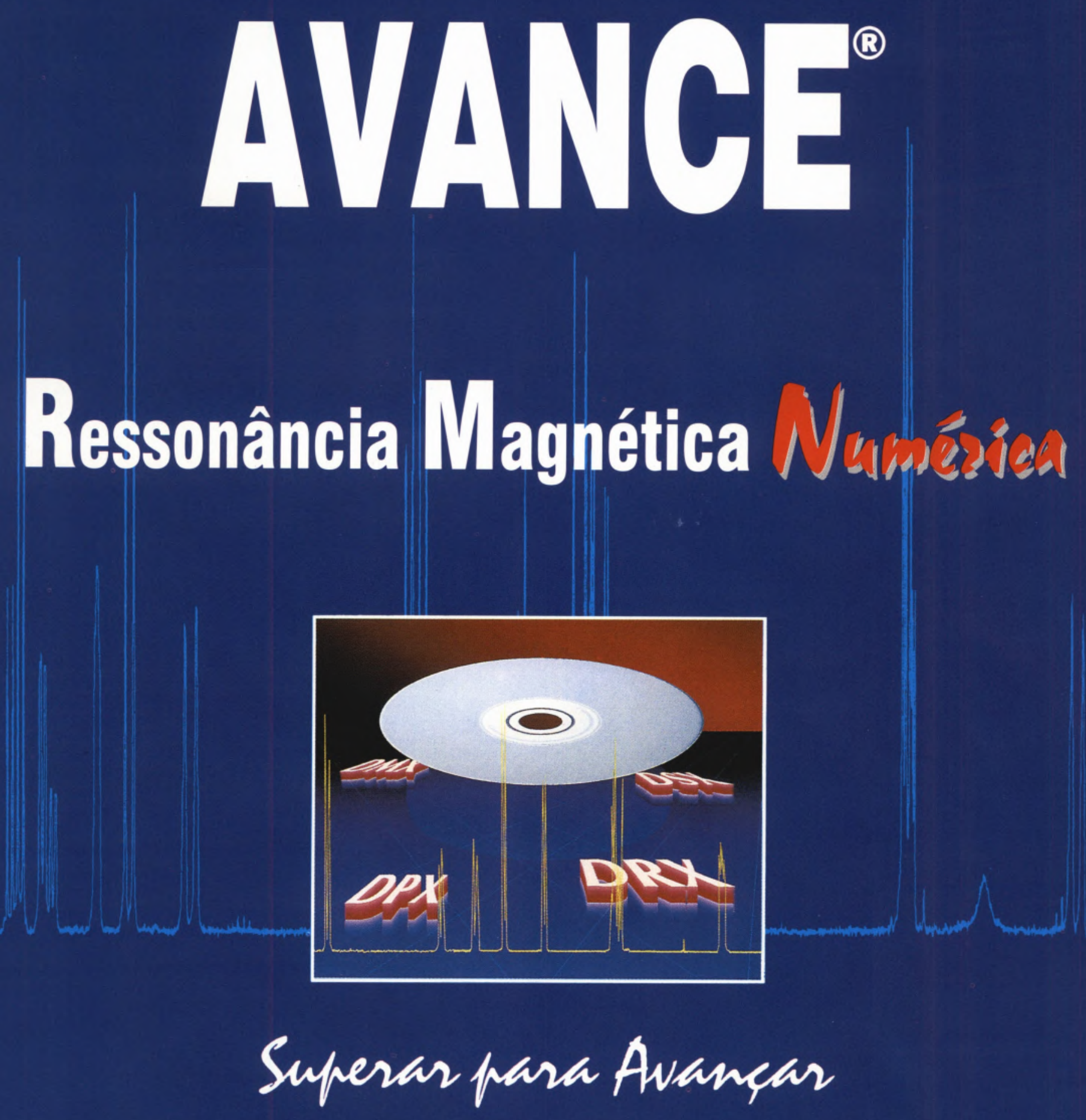

\section{GRUKER}


A precisão e a reprodutibilidade perfeitas de um tratamento numériè do sinal, são hoje universalmente reconhecidas. Esta metodologia, está, pela primeira vez na história da Ressonância Magnética Nuclear, disponível nos espectrómetros BRUKER.

Nâo confundir com conversōes de sinais analógicos em sinais digitais!

Nos espectrómetros BRUKER, NÃO HÁ CONVERSORES ANALOGICOS/DIGITAIS!

A digitalização BRUKER, na nova série AVANCE $^{\circledast}$, é feita directamente desde a excitação da amostra até ao traçado do espectro!

Esta nova série de espectrómetros, de concepção totalmente numériea, proporciona aos seus utilizadores, características revolucionárias em termos de especificaçōes, de estabilidade e de facilidade de utilizaçāo, desde as análises de rotina até à pesquisa mais sofisticada.

Uma arquitectura modular, a utilização de processadores RISC para o lock, os filtros, os geradores de sequências de impulsos ou de gradientes e a generalidade de todas as funçōes "sensíveis" do espectrómetro, fornecem a este, uma sensibilidade acrescida, uma maior dinâmica e linhas de base perfeitas, associadas a uma estabilidade sem precedentes.

\section{A série AVANCE ${ }^{*}$}

O conceito AVANCE $^{3}$, desde $200 \mathrm{MHz}$ até $800 \mathrm{MHz}$ (em funcionamento real...), foi desenvolvido para responder directamente ao pedido, cada vez mais insistente, da comunidade científica tanto Industrial como Universitária para se conseguir comercializar um sistema fácil de utilizar, eficaz e ultra estável. Deste modo, de $200 \mathrm{MHz}$ a $800 \mathrm{MHz}$, seja qual for o tema de pesquisa ou o ponto de interesse (fase líquida, sólido ou microimagem), encontrará sempre um sistema AVANCE" que satisfará perfeitamente os seus critérios.

\section{Um conceito modular: expansóes à escolha, uma manutenção fácil}

Os espectrómetros AVANCE $^{\circ}$ foram concebidos para serem totalmente modulares. Por isso, juntar um novo sub-sistema ao sistema de base, não traz qualquer problema.

Para além disso, sistemas de diagnóstico interno, inteligentes, permitem uma tele-manutençấo fácil via um circuito Ethernet ou via modem telefónico.

Filtros numérieos e super-amostragem: uma revoluçáo!

Introduzimos pela primeira vez no mundo, num espectrómetro de série, a filtragem numérica em tempo real que, associada à técnica de super-amostragem, permite a eliminação quase perfeita das ressonâncias exteriores à gama espectral, Esta tecnologia fornece ao utilizador um espectro ideal sem picos reflectidos, registado com uma dinâmica e uma sensibilidade acrescidas Em muitos casos, mas sobretudo em $2 D$ e $3 D$ a resoluçáo numérica beneficia assim de uma melhor definiçáo dos picos, dos volumes e das projecçōes.
- 2 canais de rf idênticos

- Amplificadores lineares

- "Lock" numérico

- Sobre-amostragem e filtragem numérica

- Pré-amplificadores numéricos

- Gradientes de campo B

- Acessório CPMAS (sólido de alta resolução)

- Workstation SGI Indy

- Unix, Xwindow, Motif

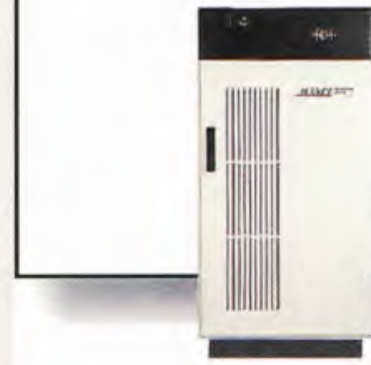

\section{"Lock" numérieo: estabilidade extraordinária}

O "lock" numérico da série AVANCE*, combina detecção em quadratura e regulação numérica por processador matemático, associados a um anel de regulação do tipo "expert".

Permite assim uma estabilidade extrema do campo estático B fornecendo resultados nunca antes alcançados em espectroscopía 2D, 3D, espectroscopía de gradientes e eliminação de água.
Características idênticas

à configuração anterior,

mais:

- Possibilidade de 8 canais rf idênticos

- Gradiente de campo

3 eixos $(X, Y, Z)$

- Micro-Imagem 


\section{A BRUKER É UMA COMPANHIA EUROPEIA}

Mas...de longe, O RECONHECIDO LIDER MUNDIAL EM ESPECTROMETRIA DE RESSONÂNCIA MAGNÉTICA NUCLEAR.

Para além da linha de produto "RMN científico", a BRUKER desenvolve e fabrica outra instrumentação médica e científica extremamente importante no domínio da Espectrometría de Ressonância Médica "in-vivo", Espectrometría de Ressonância Paramagnética de Electrões, Espectrometría de Massa, Fontes de Alimentação Ultra-estabilizadas para a indústria e pesquisa nucleares, Magnetes, etc.

Desde 1963 que a BRUKER está habituada a "Estreias Mundiais".

1963 foi o ano que viu o PRIMEIRO espectrómetro comercial "pulsado" no mundo. Em 1967, a BRUKER fabricou o PRIMEIRO espectrómetro de RMN multi-nuclear.

\section{Em 1969, a BRUKER fabricou o PRIMEIRO ESPECTRÓMETRO FT-NMR SUPER-CONDUTOR!}

E tantas outras estreias mundiais de entre as quais:

1972: o primeiro espectrómetro FT-NMR de $400 \mathrm{MHz}$.

1979: o primeiro espectrómetro de RMN comercializado, de $500 \mathrm{MHz}$.

1987: o primeiro espectrómetro de NMR comercializado, de $600 \mathrm{MHz}$.

1992: o primeiro espectrómetro de NMR comercializado, de $750 \mathrm{MHz}$.

1993: o primeiro espectrómetro de NMR comercializado, inteiramente digital.

1995: o primeiro espectrómetro de RMN comercializado, de $800 \mathrm{MHz}$.

Isto significa, que, sem qualquer dúvida, a BRUKER é a força condutora no desenvolvimento da técnica de RMN científica. Este facto dá aos seus clientes a maior confiança possível no que diz respeito à TECNOLOGIA BRUKER.

MAS SÃO AS PESSOAS QUE DESENVOLVEM ESSA TECNOLOGIA E A BRUKER, SÃO PESSOAS. $\mathrm{Na}$ realidade, mais de 1500 pessoas distribuidas por 70 fábricas e escritórios no mundo inteiro.

- A BRUKER só na Europa, no que diz respeito aos equipamentos científicos de RMN, tem 3 CENTROS DE PRODUÇẢO: um em França, directamente responsável por PORTUGAL, um na Alemanha e um na Suiça.

- A BRUKER só na Europa, tem 5 LABORATÓRIOS DE APLICAÇÕES (F,D,CH,U.K. e NL) e nesses laboratórios, EXISTEM 23 ESPECTROMETROS DE RMN entre 200 e $800 \mathrm{MHz}$ EXCLUSIVAMENTE DEDICADOS A APLICAÇÕES!

- A BRUKER só na Europa, tem mais de 30 Doutores em Química especializados em RMN, e cuja função é de ajudar os clientes a resolver problemas fundamentais ou aplicados em espectrometría de RMN.

Este investimento enorme, não é feito somente para manter a BRUKER no primeiro lugar da tecnologia de RMN, MAS TAMBÉM PARA MANTER OS SEUS CLIENTES NO PRIMEIRO LUGAR DO SEU PRÓPRIO DOMÍNIO CIENTÍFICO.

\section{A BRUKER EM PORTUGAL É:}

DIAS DE SOUSA, LDA.

Praceta Aníbal Faustino, n.6A Quinta da Piedade

2625 PÓVOA DE SANTA IRÍA

Tels. (01) $9592316 / 9594462$ (01) $9594615 / 9592409$

Fax: (01) 9590813 / 9564995

E-mail: diasdesousa@mail.telepac.pt

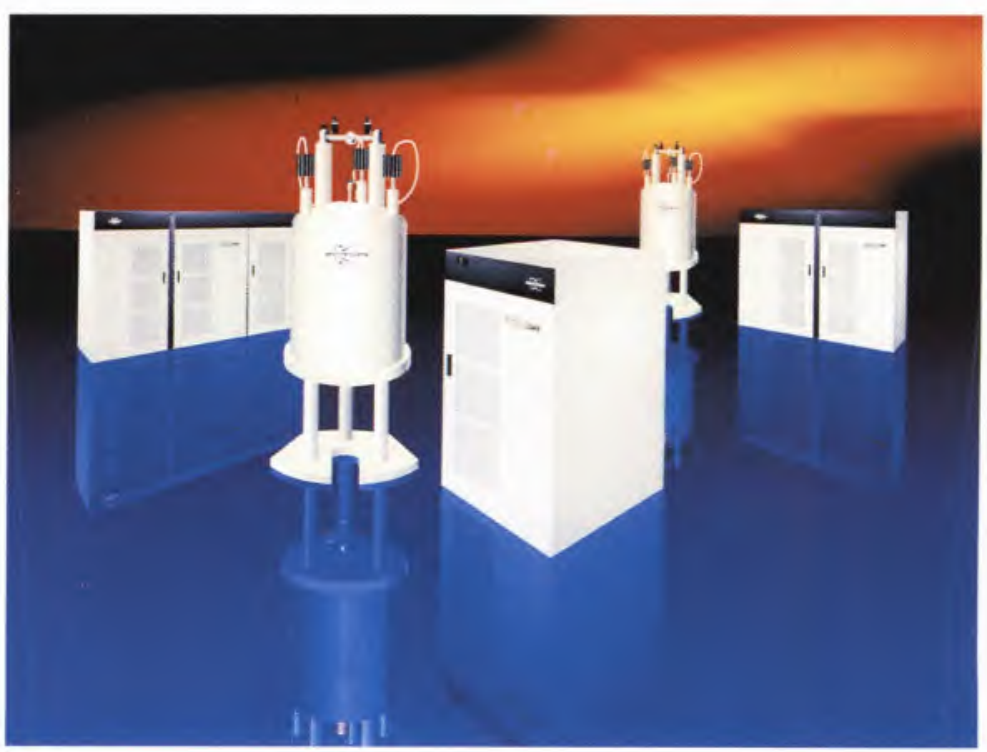


Este software intuitivo é o interlocutor ideal parà os utilizadores náo especializados ou os principiantes na técnica de RMN.

Permite $\mathrm{O}$ arranque quase imediato de uma grañde série de experiências em 1D e 2D com ou sem gradientes.

\section{ómetros AVANCE ${ }^{\circledR}$ yulares e flexíveis.}

\section{Espectroscopía de imagem, NMR em fase sólida e mais ainda. \\ SPEECTROSPIN}

A série $\mathrm{AVANCE}^{\circ}$ disponibiliza uma gama completa de aplicaçōes incluindo a espectroscopía de micro-imagem, o CPMAS, as experiências de RMN em fase sólida de banda larga, as experiências do tipo CRAMPS, etc...

Está também disponivel uma série de opções para a espectroscopía de gradientes com acessórios de gradientes $\mathrm{B}$ mono(Z) ou triaxiais $(X, Y, Z)$ e B1 (radiofrequência). O envelope dos gradientes é calculado em tempo real o que dá uma flexibilidade sem limites.

Características idênticas à configuração anterior, mais:

- Sólido de banda larga

- CRAMPS

- Magneto WB (cavidade larga)

- Espectroscopia de imagens em sólido
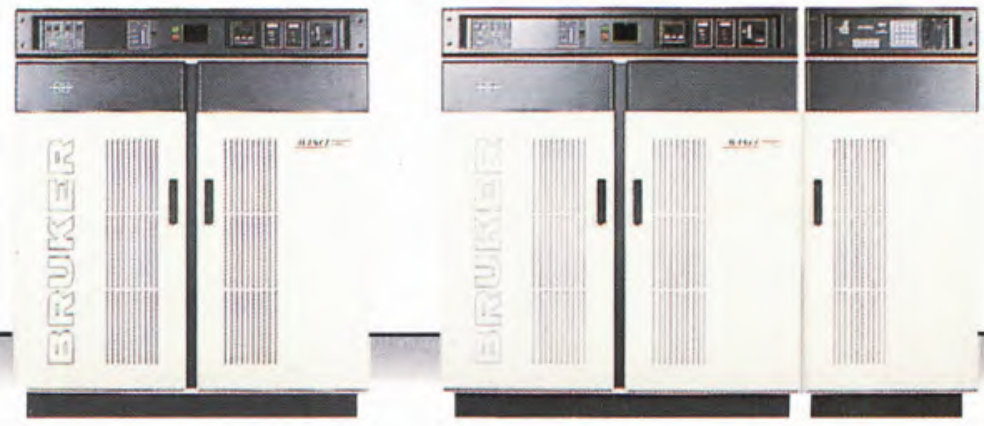

Características idênticas à configuração anterior, mas dedicado unicamente às aplicações de RMN em fase sólida.

\section{Computador e sistema de comando: facilidade de utilização}

Os computadores utilizados com os espectrómetros AVANCE $^{*}$ são correntes no mercado e funcionam em ambiente UNIX, XWindow e Motif. É o caso dos reconhecidos produtos da Silicon Graphics, nomeadamente das estaçōes Indy.

\section{XWINNMR: o software de aquisição e tratamento do sinal}

XWINNMR, a nova versão em ambiente XWindow do software UXNMR, permite o controlo das várias funçōes do espectrómetro, particularmente, e devido à sua linguagem de programaçăo flexivel e pedagógica, no que diz respeito às sequências de impulsos. O software inclui numerosas opçōes tais como cáculos de integrais em 2D, tratamento de imagens ou cáculo por entropia máxima.
Os epectrómetros podem ser equipados com amostradores automáticos para fases liquidas (para 6,60 ou 120 amostras) e para fases sólidas/CPMAS (para 20 amostras).

\section{Magnetes e sondas}

Mais de 30 anos de experiência no cáculo e na fabricaçāo de magnetes de bobina super-condutora, permitem-nos propor aos nossos clientes, magnetes com deriva extremamente baixa, ultra-estáveis e de grande autonomia em Hélio, desde $100 \mathrm{MHz}$ a $800 \mathrm{MHz}$ em valor de campo nominal e de $52 \mathrm{~mm}$ a $150 \mathrm{~mm}$ de abertura.

A BRUKER propōe igualmente a mais ampla gama de sondas estandardizadas: mistas, de 4 núcleos, de larga banda, inversas de $2,5 \mathrm{~mm}$ a $20 \mathrm{~mm}$ de diâmetro,...Sem contar com as sondas para aplicações especiais como sejam as para sólidos, para micro-imagem, CIDNP, HPLC/NMR e muitas outras.

\section{Um outro serviço: 0 após-venda}

O nosso comprometimento no domínio científico, é reconhecido e apreciado em todo o mundo. Os nossos laboratórios de aplicaçōes colaboram com numerosas equipas de pesquisa. Os nossos seminários, cursos de formação permanente e notas de aplicaçōes, fazem referência. 
de borracha existentes nos sistemas de vidro $[15 ; 22]$. Obviamente, todos estes contaminantes estão na origem de interpretações erradas, pois, quer os ftalatos quer os bifenilos policlorados podem ser tomados como pesticidas organoclorados.

\section{C.4. Filtração}

O recurso ao papel de filtro na separação do solvente extractivo após a extracção constitui, em algumas circunstâncias, uma fonte de contaminação. A presença de bifenilos policlorados neste material tem sido referida por alguns investigadores [13], pelo que, no caso particular da análise de organoclorados não deve ser utilizado. Alguns analistas referem a pré-lavagem para remover vestígios de compostos organoazotados [13], quer com n-hexano [25], quer com acetona [26; 19] e até mesmo com etanol a 96\% [11] para remover substâncias que possam interferir com a análise [27].

Quando se utiliza lã de vidro na filtração ou nas colunas de cromatografia de adsorção como "tampão", deve submeter-se a pré-lavagem com acetona e etanol, por várias vezes, e posterior secagem para proceder à remoção dos lubrificantes usados no seu fabrico [28], ou apenas com acetona [25]. Poderá efectuar-se igualmente com acetona em extractor Soxhlet durante dois dias, seguida de secagem por aplicação de vácuo e corrente de azoto [17], ou ainda submetê-la a um aquecimento de $130^{\circ}-150^{\circ} \mathrm{C}$ durante 18 horas para eliminar ou minimizar os pesticidas organofosforados previamente adsorvidos [29]. Luke et al. [28] obtiveram uma forte resposta do fósforo quando usaram lã de vidro não lavada, aquando da detecção com detectores termiónico e fotométrico de chama.

\section{C.5. Adsorventes}

Um dos processos mais vulgarmente empregues na purificação dos extractos destinados à análise de resíduos de pesticidas é a cromatogra- fia de adsorção em coluna. Alguns materiais de adsorção como o Florisil, a alumina e o óxido de magnésio são fornecidos em recipientes de plástico, pelo que se pode verificar adsorção de plastificantes e respectiva eluição aquando da utilização dos adsorventes referidos [15].

O carvão, usado principalmente na análise dos organofosforados [13; 30], origina, em certas ocasiōes, dois picos interferentes na zona do dimetoato, quando se opera tanto com o detector fotométrico de chama como com o termiónico-cloreto de potássio [31]. As impurezas de enxofre existentes em certos carvões provocam o aparecimento de um pico com tempo de retenção idêntico à aldrina [17].

A Celite 545 utilizada, por vezes, como adjuvante de filtração, provoca o aparecimento de um pequeno pico próximo do O-etil, O-pnitrofenilfenilfosfato (EPN) [31].

A alumina, a silica e o sulfato de sódio devem aquecer-se previamente numa mufla, pois, para além de fornecer o grau de actividade adequado, este procedimento destrói a matéria orgânica [32] e remove os hidrocarbonetos clorados [33].

A alumina é um adsorvente cuja lavagem é recomendada para eliminar as interferências em cromatografia gasosa. Poder-se-à processar com etanol a $95 \%$ seguida de n-hexano [34], ou com cloreto de metileno seguida de n-hexano por embebiçâo com cada solvente pelo período de uma hora [35]. Após a eliminação do último solvente deverá procederse à secagem em banho de vapor $\mathrm{e}$ posteriormente em estufa.

O gel de sílica é um adsorvente referenciado na bibliografia científica como possuidor de numerosas impurezas que interferem na análise por cromatografia gás-líquido.São exemplos dessas impurezas o ftalato de di2-etil-hexilo, os PCBs e o ácido sulfúrico [36].

A eliminação dos interferentes citados com solventes orgânicos falha na remoção das impurezas e o recurso a temperaturas de activação muito elevadas conduz a perdas dos sítios activos do gel devido à condensação dos grupos hidroxilos reactivos para formar grupos siloxanos [36; 37].

A presença de contaminantes, no gel de sílica, com tempos de retenção idênticos ao $\alpha$ - e $\gamma$-HCH em coluna DC-200, foi observada por Holden e Marsden [38] e Wells e Johnstone [41]. A sua remoção processou-se por lavagem com água destilada quente, seguida de éter dietílico, antes da activação [38]. A presença de interferências na janela de retenção do $\beta$ - $\mathrm{HCH}$ ao heptacloro epóxido (HE) foi igualmente referida [11].

Em consequência destas limitações, dever-se-á proceder à sua lavagem com água quente [38]. Outros solventes são preconizados para a sua lavagem, como a mistura acetonametanol(1:1) [39] e acetona-hexanocloreto de metileno $(1+19+80)$ [25]. A secagem em estufa será efectuada a baixas temperaturas $\left(80^{\circ}\right.$ a $\left.120^{\circ} \mathrm{C}\right)$, uma vez que o seu aquecimento a temperaturas mais elevadas, da ordem dos $200^{\circ} \mathrm{C}$, origina uma cor amarelada que resulta em brancos muito elevados [40]. Após a activação do gel de sílica, é recomendada a sua conservação a $120^{\circ} \mathrm{C}$, uma vez que se trata de um adsorvente muito higroscópico, diminuindo a resolução entre os diferentes pesticidas, com o aumento do teor em água [41].

Modernamente, as cartuchas destinadas à extracção em fase sólida com qualquer um dos adsorventes mencionados ou outros, como a sílica octadecil ligada (C18) ou sílica octa ligada (C8), são constituídas por polipropileno, contendo ftalatos como plastificantes, o que conduz ao aparecimento de picos estranhos quando se efectua a análise por cromatografia gasosa com detector de captura electrónica [42].

\section{C.6. Co-extractivos da amostra}

Na análise de resíduos de pesticidas organoclorados, com detecção por captura de electrões, a purificação dos extractos da amostra é uma operação imprescindível, dado que o detector em causa, apesar de altamente sensível, não é dotado de especificidade suficiente para os referidos compostos 
[43]. A sua finalidade reside na remoção dos co-extractivos como ceras, lípidos e pigmentos protegendo o sistema cromatográfico gás-líquido, evitando interferências na detecção e quantificação dos resíduos. Mas a aplicação do detector de condutividade electrolítica de Hall à análise de compostos organoclorados mais polares como o clorotalonil, captana e captafol, permite a supressão da purificação, simplificando a análise e tornando-a mais segura [13].

$\mathrm{Na}$ análise de substractos vegetais provenientes de repolho, grelos $\mathrm{e}$ cebolas, por exemplo, os cromatogramas obtidos com detector de captura electrónica, apresentam vários picos interferentes, o que não sucede com o detector de condutividade electrolítica de Hall [44]. No caso particular da cebola, essas dificuldades são atribuídas aos seus constituintes aromáticos voláteis como sulfuretos, tiofenos e tiosulfonatos [45].

$\mathrm{O}$ ácido 4-cloroindolil-3-acético, composto organoclorado natural, identificado nas ervilhas (Pisum sativum) por Marumo et al. [46], foi o único composto do referido grupo encontrado por Luke et al. [13] nas suas determinações com o detector de condutividade electrolítica de Hall (módulo halogéneo).

Holmes e Wood [47] referem a presença de compostos interferentes, como carotenos e sulfuretos orgâni$\cos$, que aparecem na região dos organoclorados aquando da identificação por cromatografia em camada fina. Co-extractivos oriundos de cenouras, cebolas e de crucíferas como rabanetes, repolho branco e nabos, apresentaram aquele tipo de interferentes.

Steinwandter [48] observou, em amostras de peixe, a presença constante de pentacloroanisol, na zona dos organoclorados, determinado por cromatografia gasosa capilar com detector de captura electrónica, resultante, provavelmente, da metilação do pentaclorofenol.

É necessário determinar os níveis de fundo dos materiais naturais co-extraídos, os quais podem ser confundidos com pesticidas na análi- se cromatográfica. Para esta finalidade, Sissons et al. [49] efectuaram culturas em hortas caseiras, na completa ausência de pesticidas e analisaram-nas por processo idêntico. Os resultados mostraram que nenhum dos compostos interferia na determinação de baixos níveis da maior parte dos pesticidas, mas que interferências várias poderiam ocorrer na determinação do heptacloro, do seu epóxido e, particularmente, do lindano, que têm baixos tempos de retenção na coluna SE-30. A maior parte dos compostos interferentes estava presente nos extractos de cenoura e cenoura branca na posição do lindano, dando um pico de altura máxima equivalente a $0.008 \mathrm{ppm}$. Numa coluna de fase estacionária mais polar, os dois picos foram resolvidos e nenhuma interferência significativa foi encontrada na detecção de 0.002 ppm de lindano.

Os detectores disponíveis no mercado e empregues na análise de resíduos de pesticidas organofosforados possuem alta selectividade e especificidade, permitindo em alguns extractos a sua deteç̧ão e determinação sem recurso à purificação [13]. Todavia, os co-extractivos presentes podem encurtar o tempo de vida das colunas de cromatografia gás-líquido, afectar a "performance" do detector ou provocar o aparecimento de picos interferentes [13].

Extractos de brócolos, grelos, couve-flor, cebolas e ervilhas apresentam picos significativos com o detector de condutividade electrolítica de Hall, módulo azoto e com o detector fotométrico de chama, módulo fósforo [13].

Os extractos de malagueta também produzem um pico no detector de condutividade electrolítica de Hall, módulo azoto e os de rabanete com o detector fotométrico de chama, módulo fósforo [13].

Carson [50] expressa mesmo a sua preferência pelo detector termiónico-cloreto de potássio relativamente ao detector fotométrico de chama, módulo fósforo, para extractos de vegetais provenientes de raízes como cenouras, nabos, rabanetes, cebolas e alhos devido às interferências que provocam face ao último detector. Também Sasaki et al. [51] e Braun et al. [52] referem a presença de compostos contendo enxofre nas amostras de cebola, provocando, segundo o primeiro, respostas "off-scale" quando se opera com o detector fotométrico de chama, e respostas cruzadas anómalas, no módulo fósforo, segundo o último.

\section{C.7. Efeito dos solventes} nos detectores

\section{Acetona}

Este solvente, ou qualquer outro possuidor de capacidade electrofílica, não deve ser usado na injecção de extractos destinados à quantificação com detector de captura de electrões, pois, para além de interferirem na análise, satura o detector $[15 ; 24$, p.105].

\section{Acetonitrilo}

À semelhança do cloreto de metileno e do clorofórmio, o acetonitrilo origina a deposição de sais nos detectores termiónicos, tornando-se difícil a obtenção de uma linha de base aceitável, para além de que diminui o seu tempo de vida e origina respostas de largo arrastamento nos detectores selectivos de azoto [53; 54]. Para evitar estes efeitos, procede-se à sua total remoção antes da análise por cromatografia gás-líquido com detector termiónico [55].

Cloreto de metileno

O cloreto de metileno afecta a "performance" do detector termiónico, provoca um efeito prejudicial nos purificadores de gases do detector de condutividade electrolítica de Hall (módulo azoto e módulo enxofre), origina um aumento de sensibilidade no detector de condutividade electrolítica de Hall (módulo halogéneo) [13] e no detector de captura electrónica [56]. Devido ao seu elevado coeficiente de absorção de electrões, produz um alargamento excessivo [57]. Também no detector termiónico provoca um pico de solvente negativo [58] e grande alargamento do 
solvente no detector de captura de electrões [30; 57], provocando assim interferências nos picos eluídos em primeiro lugar [59].

\section{Metanol}

Este solvente não pode ser utilizado quando se usa o detector fotométrico de chama (módulo fósforo) [60].

\section{Tolueno}

O tolueno pode causar sujidade em alguns detectores termiónicos, para além de que o pico do solvente não elui em primeiro lugar mas, posteriormente [61].

\section{C.8. Ácidos gordos}

Determinados substratos alimentares possuidores de conteúdos elevados em ácidos gordos constituem uma fonte de interferências quando analisados por cromatografia gás-líquido, mesmo após purificação por partição líquido-líquido e cromatografia de adsorção. É o caso particular do óleo de farelo de arroz cujo teor em ácido palmítico, oleico e linoleico atinge os $54,4 \%$ expresso em ácido oleico. Sonobe et al. [62] verificaram que os ácidos gordos livres podem apresentar respostas significativas quando injectados num cromatógrafo com detecção por captura de electrões ou termiónico, sucedendo o mesmo aos ésteres metílicos dos referidos ácidos quando se utiliza o segundo detector. Observaram igualmente resposta dos ácidos gordos no detector de conductividade electrolítica de Hall. Para além da ocorrência destas interferências, a contaminação dos detectores foi notória, traduzindo-se na falta de reprodutibilidade do tamanho dos picos de dia para dia, bem como no mesmo dia de trabalho, sobretudo com o detector de captura de electrões.

\section{C.9. Colunas de cromatografia gasosa}

Em alguns casos, as colunas levam a identificações erradas de alguns pesticidas, bem como a deter- minações quantitativas imprecisas, em virtude de se obterem respostas analíticas interferentes. Assim, colunas de enchimento como QF$1(6 \%)+$ SE- $30(4 \%)$ em Chromosorb WAW podem dar origem a picos com tempos de retenção idênticos para pares de pesticidas como endrina - o,p'DDT e $\alpha$-endossulfão p,p'DDE. Este fenómeno pode dar origem a interpretações erradas, pois pode concluir-se que se trata de o,p'DDT e p,p'-DDE em quantidades insignificantes, em relação aos seus níveis de tolerância relativamente elevados. No entanto, pode tratar-se de um teor muito significativo de endrina e de endossulfão, devido aos seus baixos níveis de tolerância e menor sensibilidade [17].

O p,p'DDD e o o,ṕDDT coeluem em coluna DB-17, mas separamse em coluna DB-5 [24].

A aldrina e o fenclorfos dão picos com tempos de retenção idênticos na coluna $6 \%$ QF- $1+4 \%$ SE-30 em Chromosorb WAW, com detecção por captura de electrões, sucedendo o mesmo ao heptacloro e diclofentião. Mas se a solução destes dois compostos for de $1+1$ surge apenas um pico, o mesmo acontecendo aos pares dieldrina e captana, p,p'DDT e etião, p,p'DDE, paratião e $\alpha$-endossulfão, heptacloro epóxido, malatião e paratião-metilo, pentacloronitrobenzeno (PCNB), lindano e diazinão [17].

Determinadas colunas não são capazes de separar determinados pesticidas. É o caso da coluna DC200 que não separa pares críticos de organofosforados como o par paratião-metilo e clorpirifos-metilo e o par malatião e pirimifos -metilo [63]. Se se pretende a determinação de tais pesticidas, será necessário recorrer a um enchimento mais adequado como 5\% Dexsil 300 .

A coluna $4 \%$ OV-101 (Gas Chrom.Q 80/100 mesh) não separa convenientemente o fentião e o metidatiāo, por apresentarem tempos de retenção idênticos (detector termiónico N/P). A separação pode ser conseguida com coluna 5\% OV-17 (Chromosorb G DMCS-AW 70/80 mesh) [64].
O malatião e o paratião-metilo não são separados em coluna $10 \%$ OV-210 (em Chromosorb WHP) pelo que se recorre a coluna $10 \%$ OV-101 (em idêntico suporte) para o conseguir. O mesmo sucedeu entre o paratião-metilo e o fosfamidão, na última coluna, mas a separação verifica-se utilizando a primeira coluna [24].

Como foi anteriormente afirmado, os ftalatos interferem na zona dos organoclorados. Assim, Sissons et al. [49], referem que a presença de ftalato de dibutilo interfere com a aldrina quando cromatografados em coluna $2.5 \%$ SE 30, possuindo tempos de retenção idênticos. O pico do ftalato de dibutilo na coluna de $1 \%$ QF-1 coincide com o do DDE, mas usando uma coluna de $1.5 \%$ de XE60 (ミOV-225) já não se observa qualquer interferência para os dois resíduos em questão.

Daqui surge a necessidade de recorrer à confirmação dos resultados com colunas de diferentes polaridades [24]. O não condicionamento das colunas também pode originar erros interpretativos [24].

\section{C.10. Pesticidas-Contaminantes}

A separação dos pesticidas organoclorados dos bifenilos policlorados, amplamente difundidos no meio ambiente, bem como dos terfenilos policlorados, naftalenos, alcanos, etc. é, por vezes, problemática dada a sua similaridade química e porque estes interferentes apresentam uma multiplicidade de compostos cobrindo uma ampla gama de volatilidades.

Quando se opera sobre estes compostos, a melhor forma de conseguir uma identificação e quantificação seguras consiste em injectar $o$ (s) extracto(s) convenientemente purificado(s) e separado(s) em colunas de polaridades diferentes [65].

A separação entre resíduos de organoclorados e bifenilos policlorados tem sido referenciada por vários investigadores. Enquanto uns optam pela sua separação por cromatografia de adsorção em coluna com gel de 